\section{A dinâmica do cuidado em saúde mental: signos, significados e práticas de profissionais em um Centro de Assistência Psicossocial em Salvador, Bahia, Brasil}

\author{
The dynamics of mental health care: health \\ professionals' signs, meanings, and practices in \\ a Center for Psychosocial Care in Salvador, \\ Bahia State, Brazil
}

\author{
Mônica Nunes 1 \\ Maurice de Torrenté 1 \\ Vitória Ottoni 2 \\ Valfrido Moraes Neto ${ }^{3}$ \\ Mônica Santana 1
}

\footnotetext{
${ }_{1}^{1}$ Instituto de Saúde Coletiva Universidade Federal da Bahia, Salvador, Brasil. 2 Faculdade de Medicina, Universidade Federal da Bahia, Salvador, Brasil. ${ }^{3}$ Faculdade de Filosofia e Ciências Humanas, Universidade Federal da Bahia, Salvador, Brasil.

Correspondência M. Nunes Instituto de Saúde Coletiva, Universidade Federal da Bahia.

Rua Basílio da Gama s/n, Salvador, BA 40110-040, Brasil.

nunesm@ufba.br
}

\begin{abstract}
This article analyzes the system of signs, meanings, and practices concerning mental health used by health professionals at a Center for Psychosocial Care (CAPS) in Salvador, Bahia State, Brazil. A nine-month ethnographic observation was conducted at the center, complimented by interviews and focus groups involving all staff with university and secondary schooling. Three models of care coexist at the center: the humanized biomedical model; the psychosocial model, with an emphasis on the institution; and the psychosocial model, with an emphasis on the territory, thus highlighting elements of conflict between professionals in their perception of the desired psychiatric reform and the practices to be adopted in this perspective. When compared to the asylum-based model, there is unquestionable evidence of a transformation in the care provided, mainly based on a "clinic of encounter", rooted in questioning, thinking-through, and experimenting dialogical interpersonal relationships as well as the ability to listen to the other, which explains the clinical and social impact of this approach.
\end{abstract}

Mental Health Services; Mental Health; Professional Practice

\section{Introdução}

Na história ocidental de cuidado à doença mental, modelos de reforma psiquiátrica são tão freqüentes quanto antigos. Desviat 1 apresenta os movimentos mais significativos, surgidos desde o fim da II Guerra Mundial, em países como França, Inglaterra, Itália, Estados Unidos, Canadá e Espanha. Pode-se dizer que cada um desses movimentos contribuiu com o avanço da atenção à saúde mental apresentando pontos específicos que ainda hoje são contemplados (alguns ainda como desafios) na transformação dos modelos assistenciais nesse campo. No entanto, há também distinções muito evidentes nos seus contextos históricos, concepções e objetivos, inclusive do ponto de vista social e político, o que delineia diferentes horizontes de mudanças a serem alcançados.

Um ponto em comum a todos esses modelos é a denúncia da situação manicomial e os esforços encetados na sua superação. Em todos esses movimentos, observa-se, em maior ou menor proporção, a relação concebida entre ações intra e extra-hospitalares, sendo a relação estabelecida com o espaço sócio-cultural mais vasto um aspecto que define as diferenças entre esses modelos. Nessa perspectiva, a reforma psiquiátrica italiana é aquela que parece ir mais longe na direção de uma ação política de negação dos manicômios e de todo contexto sócio-cultural que perpetue a sua existência real ou imaginária. 
Essa postura manifestou-se em atos simbólicos e concretos de grande importância como a Lei $n^{o}$. 180 de 19782 que condenava e extinguia os manicômios, o que foi progressivamente articulado a uma proposta sócio-sanitária que incluía dispositivos variados, objetivando a retirada dos doentes mentais do tradicional lugar de excluídos a partir de um investimento maciço em ações de reinserção social.

No Brasil, o movimento de reforma psiquiátrica inspira-se, em grande medida, nesse modelo italiano, iniciando em fins dos anos 70 e ganhando força em finais dos anos 80 e na década de 90. Entre os marcos da reforma psiquiátrica brasileira encontra-se a proposta de uma atenção psicossocial integrada, de uma interdisciplinaridade das práticas, de um sistema extra-hospitalar de cuidados e da defesa da cidadania dos portadores de doenças mentais ${ }^{3}$. Outro aspecto bastante em evidência refere-se à clínica que deveria orientar as ações desenvolvidas pela equipe. Muitas são as discussões e desenvolvimentos teóricos acerca deste tema, mas, em linhas gerais, há uma proposta do que é chamado de "clínica ampliada" que envolveria um conjunto de recursos que visam a trabalhar o sujeito e seus laços sociais 4 .

A década de 90 é marcada, entre outras coisas, por um processo de desospitalização seguido da criação de serviços substitutivos, processo ainda hoje considerado insuficiente face à demanda de atenção existente. Além da insuficiência quanto ao número de instituições de caráter substitutivo e, conseqüentemente, de vagas necessárias face à demanda, duas outras preocupações se adicionam: a primeira, em relação ao modo de funcionamento destas instituições e em que medida este funcionamento se aproxima do ideário da reforma psiquiátrica e, a segunda, quanto ao real formato de rede assumido pelos serviços de saúde mental e pelos serviços de atenção primária.

O presente projeto de pesquisa debruçou-se sobre essas duas questões de investigação, centrando-se, de forma preliminar, sobre duas instituições: um Centro de Assistência Psicossocial (CAPS) e uma unidade do Programa Saúde da Família (PSF), onde trabalham quatro equipes de saúde da família. O objetivo principal foi estudar como os profissionais de saúde interpretam o sofrimento mental e, para reduzi-lo, como planejam e desenvolvem suas intervenções nessas instituições. Com esse objetivo principal visavase a ter uma primeira aproximação da maneira pela qual tem se desenvolvido o cuidado em saúde mental em contexto soteropolitano, seja no âmbito de uma instituição especializada neste cuidado, seja na atenção básica. Neste artigo nos limitaremos à análise dos dados referentes ao CAPS. Parte-se da hipótese de que, em contexto especializado, como o CAPS, os desafios estariam mais concentrados na operacionalização de um novo modelo de assistência, na realização de uma experiência territorializada, participativa, integral e interdisciplinar.

\section{Estratégia metodológica}

A presente pesquisa pautou-se na metodologia denominada sistema de signos, significados e práticas em saúde mental. Trata-se de um modelo semiológico e contextual que busca identificar categorias usadas por diferentes subgrupos de pessoas para identificar, explicar e reagir a problemas de saúde mental, conformando um sistema de signos (de adoecimento), significados (atribuídos à experiência da doença) e práticas (de cuidado). Este último é acessado a partir da sua real atuação em situações concretas, o que configura uma perspectiva pragmática. Para a compreensão das múltiplas vozes que o constituem, é de fundamental importância contextualizá-las nas suas dinâmicas sociais e sistemas de valores especiais 5,6 . No caso específico deste estudo, esses subgrupos são constituídos pelos profissionais de saúde mental. Embora possamos ponderar que o sistema de signos, significados e práticas dos profissionais é orientado por uma formação acadêmica, pautada em pressupostos teóricos e em propostas terapêuticas específicas, estávamos interessados na diferença advinda das experiências particulares dos vários profissionais, dos distintos subgrupos de profissionais agregados por interesses ou valores comuns e dos múltiplos contextos de ação.

Para a produção dos dados foi realizada uma abordagem etnográfica do CAPS, que totalizou nove meses de campo, além de entrevistas semiestruturadas realizadas com todos os profissionais de nível superior, incluindo a coordenadora do CAPS, a atual e o ex-gerente do serviço de saúde mental que inclui o CAPS e um ambulatório especializado, assim como três grupos focais (o primeiro, com todos os técnicos de nível médio, os dois outros com os profissionais de ambos os níveis com o objetivo de reconstruir, de forma coletiva, casos de usuários). A etnografia teve, como foco principal, a observação do cotidiano institucional, das relações desenvolvidas entre profissionais e usuários, bem como, no interior de cada um desses grupos, das práticas desenvolvidas nos grupos terapêuticos, nas oficinas de trabalho, nas reuniões interdisciplinares, na dispensação de medicações e na triagem. Observaram-se também momentos especiais como 
passeios, comemoração de Natal, Dia das Mães e eventos como exposição de trabalhos artísticos de usuários. Essa observação foi realizada por dois assistentes de pesquisa, uma psicóloga e um estudante de ciências sociais, que registraram todas as visitas em diário de campo.

A pesquisa seguiu três etapas sucessivas, embora articuladas entre si: (1) identificação do sistema de signos apresentados pelos vários profissionais referentes aos problemas de saúde mental e seus correlatos (entre eles, foram identificados: signos diagnósticos, signos sociais ou relacionais, signos prognósticos, signos de melhora ou de piora); (2) identificação do sistema de significados atribuídos aos problemas mentais e às dinâmicas que os envolvem, e do sistema de práticas desenvolvidas para lidar com, e buscar soluções para, os mesmos; (3) reconstrução de casos concretos. Simultaneamente, fizemos questões específicas acerca da trajetória profissional dos informantes e da história institucional do CAPS.

\section{Confrontando signos, significados e práticas em saúde mental entre profissionais do CAPS}

A rotina do CAPS, o contato travado com os usuários, a qualidade das relações entre os atores que o habitam e a atmosfera de cordialidade e de amizade que reina nos seus vários espaços são alguns dos elementos que permitem concluirmos, já de início e de forma inquestionável, que esta é uma instituição que se constitui como "fonte de vida” para os usuários que a freqüentam. Essa percepção parece ser comum a todos os profissionais com os quais conversamos, com grandezas de entusiasmo diferenciados, em função do tipo de vínculo empregatício, do nível de criticidade, do modelo de prática adotado, do grau de envolvimento com o trabalho, das características pessoais etc.

Observamos que algumas das constatações do efeito benéfico desse espaço para os usuários são manifestadas sob a forma de uma intuição afetiva (que precede uma reflexão pautada em resultados), o que coloca os profissionais em uma situação desconcertante quando demandados a elaborar sobre os fatores responsáveis por esta melhora. O desconcerto parece residir exatamente no reconhecimento de que uma grande proporção desse efeito advém da humanização das relações interpessoais, fruto da ação de um conjunto de tecnologias, sofisticadas e complexas, que englobam ações de acolhimento, espaços de interlocução, estratégias de autonomização e de integralidade do cuidado.
Apesar de ser consenso entre os profissionais de que o CAPS que estudamos ainda tem muitas deficiências, fica patente a mudança do modelo de cuidado que o sustenta. Essa mudança revela muitos pontos de conflito, contradição e mesmo incoerência. Nesta apresentação, iremos apontar alguns dos âmbitos do cuidado onde ela se manifesta, ao mesmo tempo em que destacaremos algumas de suas inconsistências internas. Seguiremos como norte de análise o sistema de signos, significados e práticas revelado pelos profissionais.

Quando investigamos os signos com os quais os profissionais identificam o adoecimento mental, freqüentemente aparecem as concepções acerca do seu objeto de trabalho. Um dos momentos privilegiados no qual se revelam essas concepções é aquele da realização da "triagem", durante o qual os profissionais devem realizar uma entrevista que lhes permita decidir pela admissão, ou não, de uma pessoa como provável usuário do CAPS. Os profissionais afirmam haver um roteiro de entrevista que alveja orientá-los na perspectiva de contemplar os vários aspectos do problema: médico, social, psicológico etc. Outra orientação seria de que a triagem fosse sempre realizada por pelo menos dois profissionais, respeitando assim, na medida do possível, uma visão interdisciplinar. Observa-se que, por trás dessas orientações, situa-se o objetivo proposto pelo modo psicossocial de cuidado ${ }^{7}$ de que a pessoa seja vista em sua integralidade, dando ênfase aos fatores políticos e biopsicossocioculturais como determinantes da doença.

Na prática concreta, no entanto, essas orientações não têm sido muito respeitadas. No que se refere à triagem ser executada por mais de um profissional, isso não tem acontecido pelas mesmas razões pelas quais, segundo os profissionais, o trabalho interdisciplinar como um todo não tem sido mais realizado. Essas razões envolvem desde insatisfações salariais, que fazem com que os profissionais não se sintam mais motivados, interesses pessoais e flexibilizações informais da carga horária a fim de reduzir o nível de insatisfação, até retaliações de outros que não acham justo que apenas alguns profissionais, ou categorias de profissionais, mantenham-se implicados nessa tarefa.

Essas explicações desenvolveram-se ao longo dos relatos da história institucional que apontam para uma grande diferença entre as atitudes e grau de comprometimento dos profissionais no período de implantação do CAPS e o que eles chamam de perda de rumo do projeto institucional, em etapa posterior, atribuída à intervenção negativa da gestão municipal pregressa, quando da municipalização do CAPS. 
No que tange ao roteiro de questões elaborado para a triagem, segundo uma das profissionais, este tende mais a virar uma lista de perguntas fechadas e rotineiras, engessando a entrevista mais do que ampliando-a na perspectiva da abertura às múltiplas dimensões do adoecimento, e termina por contemplar fundamentalmente a perspectiva médica.

Informante (I): "Não, eu acho que o que está escrito lá é besteira, eu achava que podia melhorar".

Entrevistado (E): “Como?”

I: "As perguntas. Eu não tenho uma idéia assim clara, mas eu acho que poderiam perguntar coisas mais interessantes a quem chega. Tem muita coisa, assim, médica, não que eu não ache importante não, eu acho também, mas poderia ser um pouquinho diferente" (Entrevista individual no CAPS do entrevistado de número 2 - EICO2).

Há, no entanto, opiniões diferentes a esse respeito. Uma outra profissional acha importante esse questionário para padronizar mais a entrevista, impedindo que cada profissional dê ênfase ao aspecto que lhe interessa, esquecendo do interesse das outras áreas, sobretudo no contexto atual, em que a triagem é quase sempre feita apenas por um único profissional.

I: "Então, a gente tem um questionário, justamente pra gente, também, não se perder, pra cada profissional não triar da forma que achar. Então, a gente já fez um roteiro, justamente porque aî ajuda todo mundo, naquele roteiro você também não esquece e não deixa de abordar algum...".

$\mathrm{E}:$ “Aspecto...".

I: "Aspecto que seja importante".

$\mathrm{E}$ : "Esse roteiro foi feito pelo grupo, como é que foi?".

I: "Foi. Pelo, pelo (...). Como é?! Geralmente, sentou coordenadora e tal, e A, elaborou o formulário" (Entrevista individual no CAPS do entrevistado de número 1 - EICO1).

Essa profissional não parece muito crítica quanto à presença de uma hierarquia no modelo de concepção do problema de saúde mental que atribui unicamente ao médico o direito de diagnosticar os usuários. Perguntada sobre signos de doença mental, em vários momentos ela enfatiza o fato de que sua atuação resume-se a identificar sinais, mas não a definir quadros diagnósticos. Demonstra, no entanto, uma endoculturação bastante expressiva no modelo biomédico 8 , o que atribui aos anos de experiência em instituições psiquiátricas.

"Porque quem faz o (...) o (...) os sintomas, o $C I D$, geralmente, é o médico, na hora que admite o paciente, ele é que faz o diagnóstico. Eu, geralmente, trio mais, tenho uma segurança de triar mais pelos sintomas, né, ou então, o próprio pa- ciente, às vezes ele já sabe a doença que ele tem. Às vezes quando você está triando ele, ele já diz: 'oh, eu sou esquizofrênico, ah, eu sou depressivo'. Geralmente, tem uns que eles já conhecem sua patologia, ou então, a própria família, porque, pra fazer a triagem, tem que vir com o responsável, né, e, nesse momento da triagem, a gente começa a história sabendo como foi que começou a doença dele, quais foram os sintomas, como é que se caracterizavam as crises. E, a partir daí, você vai identificando, né?! Se ela vem (...) sempre pacientes esquizofrênicos, como a gente sempre vê, ou então, paciente que tem a doença que a gente chama bipolar, ou tá em mania, ou tá em depressão. Geralmente, são os pacientes que a gente tem mais por aqui. E aí, pelo sintoma, você vê se ela está na crise ou ficou agressivo, 'eu tenho alucinações', 'eu ouço vozes', né, vejo coisas, então, aí, você vai passando. Aí você vê, pelo curso do pensamento, você vê, às vezes ele tem aquela (...) aquele (...) pensamento, como é que a gente diz, assim, interrompido, não tem um curso, um discurso totalmente claro, às vezes o paciente tá lúcido, orientado, então, tá bem. Mas, você percebe aquele esvaziamento, que é da própria doença, principalmente o esquizofrênico, você percebe" (EICO1).

Em uma outra proposta semiológica, encontra-se a narrativa de uma profissional que se defende da perspectiva de identificar os usuários a partir de diagnósticos psiquiátricos. No seu discurso, fica clara a ênfase que atribui à antecedência da pessoa em relação à doença que porta, em um claro esforço de reposicionamento do sujeito no centro da sua própria história 7 na trama da doença.

I: "Eu não trabalho com as pessoas de acordo com o diagnóstico, o que não quer dizer que (...) com cada pessoa você tem uma aproximação diferente, pela sintomatologia, às vezes, é claro, você tem uma pessoa diante de você que tem freqüentemente idéias persecutórias. Eu não vou tratar essa pessoa da mesma maneira que vou tratar uma outra, que não apresente esse tipo de sintoma. Claro que eu vou me dirigir à pessoa de acordo com aquilo que ela me traz de conteúdo emocional ou psíquico, a gente pode até tentar separar essas coisas, mas acho que está tudo muito ligado, uma coisa à outra. Então, há uma abordagem diversa da minha parte, mas não porque tem aquele diagnóstico e, então, eu faço determinados tipos de ações...”.

E: "Mas, ao mesmo tempo, você sabe que tal usuário tem tal diagnóstico”.

I: "Sei. Conheço o diagnóstico que foi dado ao usuário, sem dúvida".

E: "E, depois desse diagnóstico, se é forçado a conviver com ele". 
I: "Entenda, assim, não é um elemento central para mim o diagnóstico que a pessoa recebe. Para mim o importante é como a pessoa é, que necessidades ela tem, o que ela sente. Vamos chamar de conteúdo emocional o que ela apresenta, isso sim é importante e faz parte do meu trabalho ajudar a pessoa a lidar melhor com aquilo que ela sente, porque eu nem falo de tratamento e cura, o que eu não acredito muito, mas..." (Entrevista individual com o profissional de número 4 - EICO4).

Vale ressaltar que, a despeito das contradições observadas em referência ao componente semiológico da pesquisa, ou seja, o sistema de signos, observa-se uma certa superação dessas oposições quando se associam sinais a práticas concretas. Assim fazendo, o que nos surpreendeu na análise dessas entrevistas é a que ponto o modelo asilar parece superado no que se refere à reificação de pessoas a partir de rótulos de doença, ou da ênfase absoluta atribuída à anormalidade dos doentes em detrimento do contexto no qual ele está inserido e das interrelações sociais que o constituem e que interferem no seu adoecimento. No CAPS estudado - como idealmente em qualquer CAPS -, o olhar dirige-se para fora, ainda que as ações tendam a restringir-se ao dentro da instituição. Desse modo, se analisamos, por exemplo, os critérios que priorizam a aceitação de um usuário no CAPS, verifica-se que, apesar da resposta ser que o CAPS prioriza neuróticos e psicóticos graves, na prática, observa-se o quanto a dimensão social da doença é levada em conta nas narrativas dos mais diversos profissionais. Esse aspecto revela um novo tipo de concepção de cuidado pautado na ênfase sobre as necessidades sociais dos usuários, dimensão que exploraremos mais adiante.

"Geralmente, são pacientes que já vêm de tratamento a nível ambulatorial, mas aí, a família, às vezes, tá buscando, justamente, uma outra alternativa. Não só a dele vir uma vez no mês, aí, no nível do ambulatório, pegar a medicação. São aqueles usuários, pacientes que ficam em casa sem nenhuma atividade e que a família fica naquela preocupação, ou então, aqueles que ficam muito deprimidos por não ter uma (...) então, a finalidade da gente é ressocializar esses, esses usuários, né?! A finalidade daqui da gente, também, é fazer um trabalho nesse nível, a gente trabalha tanto com eles quanto com a família. E nessa entrevista [triagem], a gente já percebe se têm um vínculo de amizade, se eles têm religião, se eles praticam, até pra gente poder conhe(...), ir conhecendo melhor aquele usuário. E a gente vê: é um usuário que só fica em casa, não se relaciona com ninguém, ou então, a própria família tem dificuldade pra se relacionar" (EICO1).
Essa mesma valorização da dimensão social aparece na avaliação realizada acerca da evolução clínica dos usuários, estando freqüentemente positivados os aspectos relacionados à reinserção social representada por diversos aspectos da vida do usuário. Desse modo, são valorizados efeitos como relacionamentos amorosos mais estáveis (como namoro ou casamento), aprendizado de um ofício, inserção no mercado de trabalho, melhora no conteúdo e intensidade das relações afetivas como amizades. Na esteira desses resultados, outros são igualmente ressaltados, como a redução na dose da medicação usada e, não menos importantes, a melhora da psicopatologia com redução, ou desaparecimento, de certos comportamentos anormais e, sobretudo, a redução das internações subseqüentes.

"Hoje, ela está com pouquíssima medicação. Já conseguiu se relacionar com uma pessoa, uma, tem uma grande amiga dela, que era daqui do CAPS, $X$ [nome da amiga]. Então, a família de $X$ adotou ela, na família" (EICO2).

"Ele trabalha numa padaria final de semana. Ele, ele é um paciente esquizo leve, né?! Paranóide, depressivo, ele chorava, chorava o tempo todo, ouvia voz quando chegou aqui. Aí, depois, ele (...) ele, agora, trabalha nessa padaria. Lida com o público. Final de semana" (Entrevista individual com o profissional de número 3 - EICO3).

"Além da melhora da psicopatologia, a inserção psicossocial também” (EICO4).

Muitos profissionais fazem uma distinção entre o que é da ordem da psicopatologia e o que é da ordem do social. Essa distinção, embora proceda, por vezes parece excessivamente dicotomizada e termina por classificar os comportamentos a priori como positivos ou negativos, segundo sua configuração no interior de quadros clínicos. Há dificuldade em interpretar sintomas como formas de articulação da experiência ou do modo de estar no mundo 9 , inscritos no contexto da história pessoal e da vida social na qual os usuários estão mergulhados.

Em situações em que essa interpretação acontece, e um sentido é produzido, chegando-se muitas vezes à conclusão de que o sintoma é uma resposta a uma desordem nas relações sociais, verifica-se que efeitos muito positivos são produzidos para o sujeito. Esses significados muitas vezes são produzidos em um contexto ampliado no qual participam a família, ou outros agentes sociais. É nesse momento que a limitação do campo de atuação ao usuário, e a não inclusão da família, reduz a intervenção terapêutica.

"É, isso. Por isso que eu estou dizendo que é importante a gente trabalhar tanto com o usuário, como a família, né, ou a família procura a gente pra fazer queixa do usuário, ou o próprio usuário 
chega fazendo queixa da família. Tem esse lado, tem os dois lados, né, e, aí, a gente percebe. É conflito? O que é que está causando esse conflito?" (EICO3).

Esses conflitos da vida social e a repercussão dos mesmos sobre os usuários são verificados quando estes retornam de períodos mais prolongados sem freqüentar o CAPS, como após feriados e finais de semana, o que gera o questionamento, por parte dos profissionais, acerca da consistência do tratamento face às dificuldades que os usuários enfrentam na vida extramuros. É nessa relação entre o dentro e o fora que residem muitos dos impasses relatados pelos profissionais do CAPS e interpretados de forma diferenciada de acordo com o modelo principal que rege a prática de cada um deles. A identificação dessas concepções e, sobretudo, de práticas diferenciadas entre os profissionais, permitem destacar três modelos de cuidado principais no interior dessa instituição.

\section{Modelos de cuidado à saúde mental no interior do CAPS}

O conflito de posições observado no que tange ao diagnóstico e concepções do objeto do cuidado em saúde mental parece refletir uma dinâmica muito significativa que aparece no CAPS estudado e que aponta para três grupos de profissionais bem delimitados segundo a compreensão do modo de cuidado em saúde mental. O primeiro desses grupos, chamamos de "modelo biomédico humanizado". Nele estariam presentes uma ênfase na psicopatologia, um cuidado assistencialista e, por vezes, tutelar, uma postura pedagógica, assumindo como principal característica a influência sobre uma mudança de comportamentos, com o objetivo de torná-los compatíveis com a reinserção social. Verificam-se ações bem intencionadas, mas, na maior parte, normalizadoras e pouco críticas.

O segundo deles constituiria o "modelo psicossocial com ênfase na instituição". Trata-se de um grupo mais centrado em uma concepção psicossocial do cuidado e em um fazer institucional pouco orientado para as práticas territoriais. Embora se perceba que nesse grupo existe uma preocupação com mudanças no fazer terapêutico, estas parecem muito adscritas à esfera teóricotécnica 7,10. Há influências mais pronunciadas da clínica psicanalítica.

Por fim, existe o grupo dos profissionais mais influenciados por um modelo territorializado, que valoriza sobremaneira os aspectos sociais do adoecimento, daí não conceberem um cuidado em saúde mental desvinculado do trabalho com as esferas familiar e comunitária, e muito preocupados com a esfera político-jurídica do mesmo 7,10. Essa forma de atuar poderia se conformar ao "modelo psicossocial com ênfase no território".

Pode-se sugerir que o segundo grupo está particularmente pautado em um modelo mais próximo da psicoterapia institucional francesa que centra fogo em mudanças intra-institucionais, enquanto que o terceiro grupo estaria radicado em um modelo mais próximo do italiano, com a ênfase antiinstitucional, pautada na defesa de devolver o doente mental à sociedade. Todos os três grupos reconhecem a importância de um cuidado que inclua outros atores sociais, além dos usuários e profissionais, e valoriza o formato aberto da instituição. No entanto, os dois primeiros tendem a ressaltar as mudanças já adquiridas como conquistas e parecem menos inquietos e insatisfeitos com a restrição espacial/territorial do projeto.

“... A demanda do psicótico, que é, claramente, uma demanda de atenção e é exatamente sobre isso que se estabelece a criação da instituição aberta, porque permite que aqueles elementos estimulantes que são negados na instituição fechada, como: o burburinho da cidade, a coisa dos vizinhos, da família, isso tudo é vedado. No CAPS, porque as pessoas vão e vêm diariamente da instituição pra casa, esse estímulo, só nesse ir e vir, é assegurado, pelo fato da pessoa se dirigir, pegar um transporte, muitas vezes, sozinho. Isso já está estimulando uma certa autonomia, uma certa garantia mínima de ir e vir" (Entrevista individual com o profissional de número 5 - EICO5).

Já o terceiro grupo vislumbra um trabalho social bastante pronunciado e busca criar fatos concretos nesta direção. Daí a participação na Associação de Usuários e Familiares, no acompanhamento dos usuários em atividades fora do CAPS, como nos passeios nos parques, na participação de manifestações e congressos da luta antimanicomial etc. Está muito mais presente aqui a importância de uma mudança cultural na sociedade, do trabalho da comunidade 5 , da participação social de grupos organizados e da organização das instituições para incluírem a participação popular, em um formato democrático. Parece haver um maior nível de frustração e de opressão desses profissionais quanto à morosidade das mudanças institucionais, o que eles atribuem também à falta de comprometimento dos profissionais. Alguns desses aspectos aparecem na narrativa abaixo:

"A minha prática cotidiana, no CAPS, é bastante limitada. O que eu faço aqui acontece, praticamente, tudo nesse mesmo âmbito. Então, até quando eu falo nas dinâmicas relacionais, eu 
trabalho com essas dinâmicas aqui dentro com as pessoas que freqüentam esse espaço. Nem com a família desses usuários eu trabalho. A minha atuação está fora da família. Então, é um trabalho extremamente limitado, naquilo que deveria ser. O que eu faço é trabalhar mais com a própria pessoa com base no conteúdo que emerge, tento ajudá-la a lidar com esses conteúdos usando vários instrumentos, alguns dos que eu falei para você e, no fundo, esperar que, algo disso que eu faço, ela possa utilizar no convívio dela cotidiano, no próprio contexto dela que é fora daqui. É muito pouco. Eu não estou falando isso nem com ironia, nem com satisfação. Eu acho que é um trabalho totalmente ineficiente e insuficiente. Ao mesmo tempo, eu não acho que seja possível realizar um trabalho desses só entre quatro paredes, eu acho que tem que estar fora, estar onde a pessoa convive, acho que muitas vezes você tem que estar em contato com a vizinhança, não é fazer entrevistas na vizinhança, mas é estar presente $e$ ter oportunidade de conversar com vizinhos, de saber como aquela pessoa está sendo vista. De repente o vizinho tem algum recurso humano, digo de relação, que pode estar colocando em jogo, que você, como trabalhador, pode tentar puxar. Mas, esse trabalho não é feito aqui, não pode ser feito aqui..." (EICO4).

Vale ressaltar que a análise desses grupos está sendo tomada como "tipos ideais", tais como concebidos por Weber ${ }^{11}$. No entanto, nem tudo é polaridade e poderíamos aventar que há vantagens e desvantagens nos pontos de vista de cada um desses grupos, como também um dinamismo inter e intragrupos, cujo espaço não permite contemplar neste artigo.

\section{Alguns importantes pontos de convergência...}

A despeito das diferenças, todos os profissionais entrevistados comungam do reconhecimento da particularidade dessa nova modalidade de cuidado em saúde mental, representada pelo CAPS. A solidez desse trabalho é atribuída ao fato dele estar, em grande medida, alicerçado no questionamento, na reflexão, na elaboração, e, sobretudo, na experimentação de relações interpessoais mais dialógicas e na escuta do outro, o que justifica o impacto clínico-social do mesmo. $\mathrm{Na}$ ausência de um trabalho de base territorial, muita coisa é inventada nesse microcosmo, na microfísica dos poderes e das relações sociais que o habitam. Aí parece residir a força e a delicadeza dessa instituição. De lugares diferentes, os vários profissionais parecem destacar esse aspecto como ferramenta transformadora:
E: "No caso, sua participação em particular nessa oficina, você ensina?”.

I: "Ensino, se chegar também querendo conversar, bater um papo, um diálogo, perguntar qualquer coisa, eu tô pronta a responder; ao meu alcance, eu vou falar com muito cuidado pra não prejudicar" (Primeiro grupo focal do CAPS - GFCO1).

"Eu, basicamente, trabalho com duas coisas. Uma é o verbal, a conversa. Com base naquilo que a pessoa vai falando, aparece o que ela está sentindo naquele momento, esse é um. (...) A outra coisa que eu utilizo, mas aí é só com as pessoas que utilizam o grupo que eu faço, é ver as dinâmicas de relações que estão acontecendo durante o grupo, que também revela, às vezes, uma série de coisas sobre o que cada um está vivendo" (EICO4).

Relações interpessoais e interações sociais são compreendidas como a base do existir humano e antecedem mesmo as técnicas terapêuticas, inscrevendo-se na dimensão cidadã e política do cuidado. As características, modalidades de desenvolvimento e objetivos desse cuidado aparecem de forma radicalmente diferente quando comparados ao modus operandis presente no modelo asilar. Neste último, como bem evidencia Goffman 12, há uma tendência à mortificação do sujeito, à produção de uma "carreira de doente" e à regressão nas formas humanas de relação, limitando-se a necessidades muito primárias das pessoas, como destacado abaixo:

"O que eu tenho observado, nessa experiência pessoal em trabalhar no CAPS, é que a condição de número, a condição de elemento pacificado, de doente encontrado no hospital psiquiátrico fechado, situa-se em contraposição a essa nova instituição aberta que acolhe a família, acolhe os valores da comunidade em volta e, basicamente, acolhe as aspirações desse sujeito entre os usuários. A gente nota que o exercício, que torna isso possível através de atividades manuais, discussões sobre questões particulares ou coletivas dos usuários, atividades musicais, teatrais, artesanais (...). Pessoas, mesmo que comprometidas por idéias delirantes, com alucinações, até mesmo com defeitos comportamentais relativamente graves, conseguem, com um plano que prioriza qualidade de vida, restaurar certos traços de auto-estima, de auto-respeito. As relações aqui entre os usuários são incomparavelmente diferentes as das relações do hospital clássico, que estão, assim, mais fundamentadas no prazer imediato: 'me dê um cigarro', o abuso sexual, a briga por comida. Isso, numa instituição aberta, já é bem diferente, porque a gente nota que há os valores do relacionamento, que testemunham, assim, que um estágio mais evoluído se faz presente: a solidariedade. Às vezes é enternecedor você ver, assim, certos rasgos de ge- 
nerosidade dos usuários, que dão coisas que muitas vezes não podem dar. Enfim, cria-se então essa comunidade que tem como objetivo estimular o indivíduo para que ele consiga trazer à superfície do seu ato, da sua praxe, algo de seu. Que sugere uma reestruturação subjetiva mesmo, além dos cuidados médicos que aqui também são prestados" (EICO5).

Salientam-se avanços do trabalho clínico, centrados no que aqui chamamos de uma "clínica do encontro", pautada no diálogo, na escuta interessada, na produção de intersubjetividades, na troca, na partilha. Dessa clínica pode advir a emergência do sujeito como descrito por vários autores que falam de uma clínica do sujeito 13 ou de uma clínica ampliada 14 . Vale ressaltar que esse "ponto de viragem" ancora-se na observação de aspectos fundamentais que precisam estar presentes e serem alvo de reflexão, articulados em uma prática que enfrente a complexidade do cuidado.

Um desses aspectos refere-se ao campo epistemológico e clínico, ligando-se a teorias, saberes, conceitos e técnicas de cuidado, o que deveria ganhar maior transparência nas instituições de saúde mental. Nesta pesquisa, o que emergiu foi a escassez de discussões acerca dos aspectos teórico-metodológicos que envolvem os diversos modelos de cuidado coexistentes nessa instituição. Nesse sentido, um mesmo usuário pode estar sendo visto a partir de múltiplos olhares sem que essa multiplicidade seja objeto de reflexão. Se, de um lado, se aceita a pluralidade como riqueza, não se pode esquecer que, por vezes, há práticas e idéias concorrentes, ultrapassando a mera complementaridade. A ausência de certos pontos de concordância pode aumentar a angústia e fragmentação do sujeito, que já possui um sofrimento psíquico, ao invés de contribuir com a sua melhora. Além disso, algumas práticas e idéias podem funcionar de forma antiterapêutica, ou agir de forma tão restritiva e convencional, a ponto de reproduzir o modelo asilar controlador, repressor, segregador e excludente.

O segundo aspecto diz respeito à integralidade do sujeito e à interdisciplinaridade do cuidado. O reduzido diálogo interprofissional impede uma real prática interdisciplinar, mantendo a configuração da sobreposição de saberes. Nesse caso, trata-se menos da corrente teórica de ado- ção do profissional (psicanalítica, psicodrama, cognitivismo etc.), e muito mais da dimensão do sujeito que ele privilegia na sua clínica (biológica, social, psicológica, cultural, política etc.). Enquanto, no primeiro aspecto, nota-se haver pouca tendência à intercessão, muitas vezes vista como um sincretismo indesejável e incoerente, no segundo, é crescente o reconhecimento da importância de se buscar articulações nas formas de integralidade do cuidado, o que pressupõe valorizar igualmente todas as dimensões constitutivas do sujeito.

A observação desses aspectos do cuidado exige dos cuidadores conhecimento técnico e comprometimento sócio-político, habilidade em lidar com a diferença e responsabilidade com a vida de cada pessoa que o busca, motivação profissional e valorização do seu trabalho. Essas qualidades articulam-se com o compartilhamento dos ideais da reforma psiquiátrica e com uma prática cotidiana crítica, reflexiva e criativa. Para isso acontecer, há que se dispor de condições de trabalho favoráveis, de espaços de supervisão, de uma rede de cuidados em saúde mental, que retire os serviços da condição de isolamento, e de espaços de formação permanente que permitam trocas de pensamentos e de experiências entre os profissionais e os serviços, capazes de lutar contra o enrijecimento dos desejos e dos fazeres dos sujeitos cuidadores.

Como se pode notar, o processo de mudança, ainda que fortemente estimulado por políticas públicas, se produz verdadeiramente de dentro para fora, no cotidiano dos serviços, na experiência de encontros e desencontros entre seus atores sociais, dos seus acertos, tentativas de acertos e erros. A possibilidade de manter um olhar reflexivo e contextualizado sobre essa práxis nem sempre tem sido contemplada no espaço institucional. A rotina do trabalho, aliada à dificuldade de uma distância ótima, limita a produção de interpretações críticas e até mesmo da "violência interpretativa" 15, necessária para o avanço na direção almejada. Do mesmo modo, essa vivência imersa e absorta no fluxo da experiência pode favorecer o mergulho nos problemas, a asfixia gerada pelo sentimento de impotência e de insatisfação, impedindo a justa apreensão das conquistas alcançadas e dos giros da espiral. 


\section{Resumo}

O presente artigo analisa o sistema de signos, significados e práticas em saúde mental utilizado por profissionais de um Centro de Atenção Psicossocial (CAPS) situado em Salvador, Bahia, Brasil, com oito anos de implantação na época da pesquisa. Para tanto se realizou, durante nove meses, uma etnografia do serviço, complementada por entrevistas e grupos focais com todos os profissionais de nível universitário e de nível médio. Entre os principais resultados, identifica-se a coexistência de três modelos de cuidado nesse CAPS: o modelo biomédico humanizado, o psicossocial com ênfase na instituição e o psicossocial com ênfase no território, revelando pontos de conflito entre os profissionais na forma de vislumbrar a Reforma Psiquiátrica desejada e o alcance das práticas nesta perspectiva. A despeito das diferenças, há uma evidência inquestionável de transformação do cuidado quando comparado ao modelo asilar fundado principalmente em uma "clínica do encontro", alicerçada no questionamento, na reflexão e, sobretudo, na experimentação de relações interpessoais mais dialógicas e na escuta do outro, o que justifica o impacto clínico-social desta clínica.

Serviços de Saúde Mental; Saúde Mental; Prática Profissional

\section{Referências}

1. Desviat M. A reforma psiquiátrica. Rio de Janeiro: Editora Fiocruz; 1999.

2. Reppublica Italiana. Legge $n^{\circ} .180,13$ maggio 1978. Accertamenti e trattamenti sanitari volontari e obbligatori. Gazzetta Ufficiale 1978; 16 mag.

3. Delgado P. Atendimento psicossocial na metrópole: algumas questões iniciais. Cadernos IPUB 1999; 14:113-21.

4. Bezerra Jr. B. A clínica e a reabilitação psicossocial. In: Pitta A, organizador. Reabilitação psicossocial no Brasil. 2ạ Ed. São Paulo: Editora Hucitec; 2001. p. 137-42.

5. Corin E, Bibeau G, Martin JM, Laplante R. Comprendre pour soigner autrement: reperes pour régionaliser les services de santé mentale. Montréal: Presses de l'Université de Montréal; 1990.

6. Corin E, Uchôa E, Bibeau G, Koumare B. Articulation et variations des systèmes de signes, de sens et d'actions. Psychopathologie Africaine 1992; 24:183-204.

7. Costa-Rosa A. O modo psicossocial: um paradigma das práticas substitutivas ao modo asilar. In: Amarante P, organizador. Ensaios, subjetividade, saúde mental, sociedade. Rio de Janeiro: Editora Fiocruz; 2000. p. 141-68.

8. Good B. Medicine, rationality and experience: an anthropological perspective. Cambridge: Cambridge University Press; 1994.

\section{Colaboradores}

M. Nunes, M. Torrenté e V. Ottoni contribuíram na redação do presente artigo. V. Moraes Neto e M. Santana colaboraram na produção de dados de campo. M. Santana participou da revisão do texto final.

\section{Agradecimentos}

Esta pesquisa contou com a participação de Alexandre Amaral, Vládia Jucá, Carla Valentim e Suely Barreto.

9. Corin E, Lauzon G. From symptoms to phenom ena: the articulation of experience in schizophrenia. Journal of Phenomenological Psychology 1994; 25:3-50.

10. Amarante P. A (clínica) e a reforma psiquiátrica. In: Amarante P, organizador. Arquivos de saúde mental e atenção psicossocial. Rio de Janeiro: Nau Editora; 2003. p. 45-66.

11. Weber M. Essais sur la théorie de la science. Paris: Plon; 1992

12. Goffman E. Asylums: essays on the social situation of mental patients and other inmates. New York: Ancher Books; 1961.

13. Lobosque AM. Clínica em movimento. Rio de Janeiro: Editora Garamond; 2003.

14. Tenório F. A psicanálise e a clínica da reforma psiquiátrica. Rio de Janeiro: Editora Rios Ambiciosos; 2001.

15. Bibeau G, Corin E. Introduction. In: Bibeau G, Corin E, editors. Beyond textuality. New York: Mouton de Gruyter; 1995. p. 2-69.

Recebido em 29/Set/2006

Versão final reapresentada em 22/Fev/2007

Aprovado em 28/Mai/2007 